\title{
HUBUNGAN CAPITAL STRUKTUR DENGAN NILAI PERUSAHAAN PADA PERUSAHAAN PERTAMBANGAN BATUBARA YANG TERDAFTAR DI BURSA EFEK INDONESIA 2014-2019
}

\author{
1)Andri Faisal, ${ }^{2)}$ Kampono Imam Yulianto \\ Email: 1)faisalforlan@gmail.com 2)kamponoyulianto@yahoo.co.id \\ 1)Program Studi Manajemen, Fakultas Ekonomi \\ 2)Program Studi Akuntansi, Fakultas Ekonomi \\ 1) 2)Institut Bisnis dan Informatika (IBI) Kosgoro 1957
}

\begin{abstract}
ABSTRAK
Perusahaan pertambangan adalah perusahaan dengan modal besar yang sering kali meminjam dari pihak lain. Peminjaman atau hutang akan mempengaruhi dari suatu nilai perusahaan, Penelitian ini bertujuan untuk menguji apakah ada hubungan antara struktur hutang terhadap nilai perusahaan yang dalam hal ini diwakilkan oleh Tobin q. Sampel Penelitian ini adalah perusahaan pertambangan yang terdiri dari perusahaan pertambangan batu bara yang terdaftar di Bursa Efek Indonesia. Pengolahan data dengan menggunakan data Panel yang terdiri dari enam perusahaan dan dalam rentang waktu 2014-2018. Hasil regresi menunjukkan nilai debt to asset ratio berhubungan signifikan dengan nilai perusahaan dengan derajat kesalahan lebih kecil dari 5\%, sementara nilai debt to equity ratio tidak signifikan. Dengan hasil uji $\mathrm{F}$ terlihat bahwa kedua variabel tersebut memengaruhi secara bersamaan, dibuktikan dengan nilai $\mathrm{F}$ lebih kecil dari 0.05 .
\end{abstract}

Kata Kunci: Struktur Hutang, Saham Pertambangan, Tobin Q

\section{PENDAHULUAN}

Perusahaan pertambangan adalah salah satu badan ekonomi yang bertujuan untuk mengeksplorasi sumber daya alam untuk kepentingan khalayak banyak. Bahan tambang yang dibutuhkan untuk kelangsungan manusia baik untuk bahan bakar atau barang tambang yang digunakan untuk bahan-bahan baku dalam industri strategis. Usaha pertambangan memiliki kontribusi yang besar terhadap pembangunan negeri ini karenanya usaha ini seharusnya bisa berjalan senantiasa agar bisa memberikan kontribusi yang nyata bagi pembangunan negeri ini.

Prospek batu bara pada saat ini kurang menguntungkan dengan terjadinya penurunan harga saham lebih dari 50\% (Kurniawan, 2008). Penurunan ini akibat harga batu bara yang menurun juga dan dapat menurunkan nilai perusahaan tersebut. Penurunan pendapatan akan 
menyebabkan perusahaan harus mengisi kebutuhan modal untuk terus tetap beroperasi. Perusahaan harus dapat mengatur strategi meski harus meminjam namun mempertahankan nilai perusahaan agar tetap sehat.

Untuk menjamin usaha yang sehat dan berkesinambungan diperlukan permodalan yang cukup baik dari sisi internal maupun eksternal. Sering kali perusahaan yang mempunyai sifat padat modal ini harus meminjamkan uang dari, pihak lain seperti lembaga keuangan yang mensyaratkan pengembalian beserta biaya. Selain itu perusahaan juga dapat meminjam uang pada khalayak yang akan diberi balasan berupa bagi hasil. Perusahaan dapat memberikan saham pada pemberi modal. Sebuah perusahaan harus mendapatkan formula yang pas agar bisa menyeimbangkan pendanaan yang dapat meningkatkan keuntungan dari perusahaan tersebut. Keuntungan perusahaan akan membuat nilai perusahaan yang semakin baik yang menjadi tujuan dari perusahaan.

Dari uraian di atas, riset ini mempunyai permasalahan hubungan struktur modal (DER) dengan nilai perusahaan, rasio modal dengan aset (DAR) serta hubungan yang simultan antara nilai perusahaan dengan struktur modal serta dengan rasio modal dan aset.

1) Adakah hubungan DER terhadap Tobin Q?

2) Apakah Hubungan DAR terhadap Tobin Q?

3) Adakah hubungan simultan DER dan DAR terhadap Tobin Q?

Sesuai dengan arah permasalahan yang dirumuskan maka hipotesis adalah seperti di bawah ini:

H1: Terdapat Hubungan antara Struktur Modal (DER) dengan Nilai Perusahaan (Tobin Q)

H2: Terdapat Hubungan antara Rasio Modal (DAR) dengan Nilai Perusahaan (Tobin Q)

H3: Terdapat Hubungan Simultan antara Struktur Modal (DER) dan Rasio Modal (DAR) dengan Nilai Perusahaan (Tobin Q) Struktur Modal 


\section{TINJAUAN PUSTAKA}

Struktur Modal adalah suatu pembiayaan jangka panjang yang mengikutkan modal sendiri maupun hutang diukur dengan perbandingan total hutang dengan modal sendiri. Teori struktur modal akan mencakup pengaruh pembiayaan jangka panjang terhadap nilai perusahaan, biaya modal, harga saham. Pembiayaan akan meningkatkan nilai dari perusahaan kalau saja perusahaan dapat menaikkan kinerjanya. Jika nilai sebuah perusahaan akan meningkat maka harga sahamnya akan meningkat juga (Sudiana, 2019).

Jika kita melihat sebelah kanan adalah sebuah kewajiban maka sebelah kiri adalah sebuah aset atau kekayaan. Jika suatu aset atau kekayaan adalah milik yang dipunyai oleh perusahaan. Sedangkan kewajiban adalah sebuah struktur keuangan yang terdiri dari hutang dan juga ekuitas. Jika hutang terbagi dalam dua bagian baik hutang jangka panjang maupun hutang jangka pendek. Hutang jangka pendek yang harus dipenuhi oleh sebuah perusahaan dalam waktu yang spontan atau kurang dari waktu satu tahun. Sedangkan jangka panjang adalah dana yang terpakai sebelum waktunya akan dipakai. Untuk modal karena itu struktur modal diperhitungkan ekuitas dan hutang jangka panjang saja (Mardiyanto, 2009).

Perusahaan mencari dana untuk mengembangkan perusahaan kadang butuh hutang. Di sisi kiri ada aset dan di sisi kanan ada harta perbandingan hutang, saham, dan saham lainnya (Corelli A, 2018). Perusahaan dapat mempunyai saham yang tidak perlu dikembalikan pada pemberi pinjaman namun harus membagi untung. Tentu saja perusahaan yang mempunyai kemampuan untuk membayar hutang. Perusahaan yang tidak sanggup bayar hutang akan menyebabkan perusahaan bangkrut.

Debt to Equity ratio adalah salah satu rasio yang termasuk dalam laporan keuangan (Anderei, 2019). Rasio ini membandingkan antara keseluruhan hutang dengan nilai ekuitas yang dimiliki perusahaan. 
Debt to Equity ratio adalah suatu kemampuan untuk memenuhi kebutuhan jangka Panjang (hutang jangka Panjang). Semakin kecil rasio semakin baik dan menunjukkan dari risiko likuiditas perusahaan, (Gibson 2012).

Debt to Asset Ratio adalah hubungan antara hutang dengan aset. Ini adalah rasio seluruh kewajiban dengan harta atau aset yang dimiliki oleh perusahaan, Debt To Asset Ratio disebut juga rasio hutang adalah sebuah rasio pengungkit (leverage) yang menunjukkan persentase aset yang dibiayai oleh hutang. Semakin tinggi rasio semakin tinggi derajat leverage dan semakin tinggi juga risiko keuangan (Anderson, 2013:41-43).

Tobin $Q$ adalah suatu metode yang dipergunakan untuk menghitung nilai perusahaan. Untuk menghitung Tobin $Q$ diperlukan data harga saham dan total hutang perusahaan. Formula Tobin $Q$ ratio adalah market equity yang merupakan perkalian dari harga saham pasar pada saat itu dengan jumlah saham yang beredar di bursa. Nilai pasar saham (market equity) dikurangkan total hutang perusahaan, baik hutang jangka pendek dan hutang jangka pendek. Selisih nilai tersebut dibagikan dengan total aset dari perusahaan.

Tobin' $Q=\frac{M E-D e b t}{T A}$

Dalam penelitian ini menggunakan beberapa variabel penelitian yang sedikitnya terdiri dari satu variabel independen atau variabel bebas. Dalam penelitian ini variabel bebas adalah rasio struktur modal.

Seperti kita ketahui kalau modal dalam perusahaan terbuka atau perusahaan yang sudah go public adalah surat hutang dan juga saham. Seperti sudah dibahas di atas kalau kedua modal ini membentuk perusahaan ke dalam perusahaan 


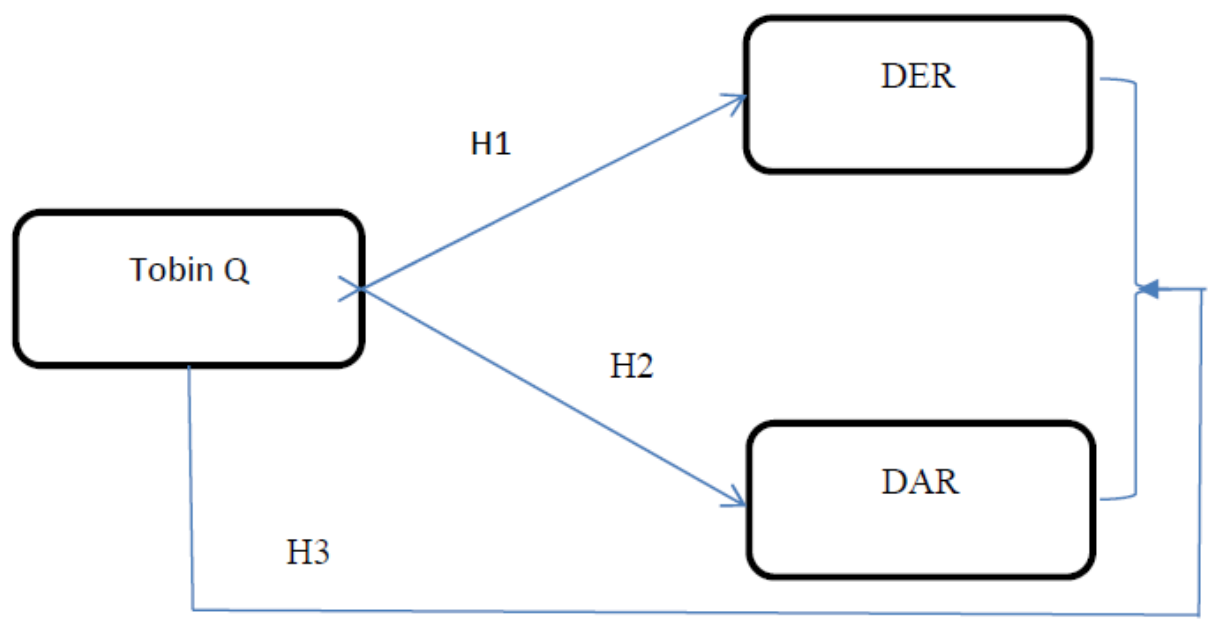

\section{Gambar 1. Kerangka Penelitian}

\section{METODE PENELITIAN}

Penelitian ini berfokus untuk mencari pengaruh struktur modal terhadap nilai perusahaan pada perusahaan pertambangan sub sektor pertambangan batu bara selama 2014-2018. Penelitian menggunakan data sekunder dan dilakukan selama bulan Maret-April 2020. Data-data perusahaan pertambangan diperoleh dari www.idx.co.id. Ada beberapa lis dalam perusahaan yang menjadi sampel.

Tabel 1. Daftar Perusahaan Pertambangan 2014-2018

\begin{tabular}{clc}
\hline NO & \multicolumn{1}{c}{ NAMA PERUSAHAAN } & $\begin{array}{c}\text { SUB SEKTOR } \\
\text { TAMBANG }\end{array}$ \\
\hline 1 & Adaro Energy, Tbk & Batu Bara \\
\hline 2 & ATPK Resources, Tbk & Batu Bara \\
\hline 3 & Bumi Resources, Tbk & Batu Bara \\
\hline 4 & Bayan Resources, Tbk & Batu Bara \\
\hline 5 & Indo Tambang Raya Megah, Tbk & Batu Bara \\
\hline 6 & Resource Alam Indonesia, Tbk & Batu Bara \\
\hline 7 & Tambang Bukit Batubara Bukit Asam, Tbk & Batu Bara \\
\hline 8 & Petrosea, Tbk & Batu Bara \\
\hline
\end{tabular}

Sumber: Data Diolah (2020)

Pengolahan data dalam penelitian ini adalah regresi data panel; yang mencakup individual perusahaan yakni perusahaan pertambangan batu bara dan juga dimensi waktu yakni antara tahun 2014-2018. Untuk mempermudah perhitungan data panel dengan menggunakan software 
RStudio Versi 4.0.2. Regresi panel data akan melakukan beberapa tahap. Setidaknya ada tiga metode regresi akan dicobakan untuk mencari model yang paling efisien yang dapat menduga atau meramalkan hubungan antara Nilai perusahaan Tobin $Q$ dengan struktur modal yakni, Debt to Equity Ratio (DER) dan Debt to Asset Ratio (DAR). Adapun uji-ujinya seperti tahapannya adalah berikut ini:

1) Uji Individual Effect, Uji ini dilakukan untuk menentukan adanya efek individual dalam model regresi data panel. Pada uji ini akan memilih model yang tepat antara fixed effect dengan metode Pooling.

2) Uji Random Effect, Uji ini dilakukan untuk memilih metode yang paling tepat antara random effect atau pooling.

3) Uji Hausman, Uji ini untuk menentukan model yang paling tepat antara fixed effect atau random effect.

4) Melakukan regresi metode yang terpilih sesudah ketiga uji di atas. Hasil regresi ini akan menghasilkan persamaan regresi dari suatu model yang paling tepat dan untuk selanjutnya diuji dulu asumsi klasiknya.

5) Uji asumsi klasik, adalah uji yang menentukan apakah model yang terpilih terbebas dari gejala yang dapat menyebabkan hasil regresi menjadi bias atau tidak valid. Adapun uji itu terdiri dari:

a. Asumsi Normal

Dalam penelitian ini yang menggunakan metode regresi berganda membutuhkan data yang terdistribusi dengan normal. Data tersebut dapat dianalisis dengan metode yang nantinya akan dipakai dalam analisis regresi data panel ini. Jika ternyata data terdistribusi tidak normal, maka dilakukan beberapa perbaikan.

b. Multikolinearitas

Jika ada hubungan antara variabel independen dan dependen maka hal itu adalah hal yang baik bagi sebuah analisa regresi 
akan tetapi jika ada hubungan sesama variabel bebas maka hal tersebut akan merusak uji asumsi klasik.

c. Heteroskedatisitas

Dalam penggunaan metode regresi terkadang dijumpai heteroskedatisitas yang terjadi karena galat yang berubahubah atau tidak konsisten. Ketidakkonsistenan galat (error) dapat menyebabkan estimasi menjadi tidak konsisten (heteroskedastitas). Akibatnya nilai atau hasil regresi yang dihasilkan tidak sah atau bias

d. Autokorelasi

Data panel dapat diduga mengandung autokorelasi karena sifat data runtut waktu atau time series mengandung autokorelasi. Adanya autokorelasi akan menyebabkan hasil regresi tidak sah atau bias.

\section{HASIL PENELITIAN DAN PEMBAHASAN}

Setelah melewati beberapa tahapan penelitian kita melihat secara kasat mata kalau perusahaan tersebut sedang mengalami beberapa permasalahan yang sudah kita bahas sebelumnya. Kita melihat dari statistik deskriptif dari kedelapan perusahaan pertambangan yang menjadi sampel maka akan terlihat perusahaan yang memiliki TobinQ besar adalah sebagai berikut:

Tabel 2. Statistik Deskriptif Perusahaan Pertambangan Sub Sektor Batubara 2014-2018

\begin{tabular}{|l|c|c|c|}
\hline & DAR & DER & Tobin Q \\
\hline Min. & 0,1400 & $-7,1700$ & $-1,4735$ \\
1st Qu. & 0,3200 & 0,4175 & $-0,2456$ \\
Median & 0,4200 & 0,6900 & 0,3332 \\
Mean & 0,5385 & 1,0355 & 0,5902 \\
3rd Qu & 0,5900 & 1,0550 & 1,1209 \\
Max & 1,9000 & 11,9100 & 5,1768 \\
\hline \multicolumn{3}{|c}{ Sumber : Data Diolah (2020) }
\end{tabular}


Nilai terendah dari Tobin $Q$ adalah $-1,4375$ sedangkan nilai maksimumnya adalah 5,1678 . Nilai Tobin $Q$ yang rata-rata hanya 0,5902 menunjukkan besarnya nilai simpangan yang terjadi pada nilai Tobin $Q$. Untuk Nilai Struktur hutang DER Nilai terendah -7.170 dengan nilai maksimum 11,91. Untuk nilai DAR terendah 0,14 dengan nilai tertingi 1,9 yang menunjukkan nilai yang tidak menunjukkan variasi yang banyak.

Analisis selanjutnya adalah regresi data panel. Memulai dengan prosedur berdasarkan yang disebutkan di atas dan model yang estimasinya mendekati adalah Generalized Least Square yang mengabaikan heteroskedastisitas atau gangguan galat yang terjadi akibat perbedaan galat dengan setiap regresi dan juga adanya pola waktu yang mengakibatkan terjadinya kesalahan dalam estimator (autokorelasi). Pertimbangan penggunaan ini karena penggunaan Pooling tidak lolos maupun penggunaan Fixed Effect. Ujinya menunjukkan sebagai berikut:

1) Pertama, melakukan regresi data panel dengan metode pooling dan dilanjutkan regresi dengan model Fixed Fffect. Uji antara Pooling dengan Fixed Effect dengan menggunakan uji efek Individual.

$\mathrm{Ho}=$ Regresi Panel Pooling

$\mathrm{Ha}=$ Regresi Panel Fixed Effects

$F$ test for individual effects data: Tobinq DAR + DER $\mathrm{F}=13.701, \mathrm{df} 1=7, \mathrm{df} 2=30, \mathrm{p}$-value $=8.309 \mathrm{e}-08$ alternative hypothesis: significant effects

Hasil ujinya menunjukkan nilai $p$ ( $p$-value) dibawah 0,05 , artinya hipotesis nol ditolak dan hipotesis alternatif yang diterima. Hal ini menunjukkan adanya efek individual pada hasil regresi tersebut. Karena adanya efek individual maka model yang lebih tepat digunakan adalah Fixed Effect untuk sementara ini.

2) Kedua, melakukan uji Langrange Multiplier atau LM dengan tujuan untuk mencari apakah ada efek random dalam data tersebut.

Ho $=$ Regresi Panel Pooling

$\mathrm{Ha}=$ Regresi Panel Random Effects 
Lagrange Multiplier Test - (Honda) for balanced panels data: Tobinq DAR + DER normal $=5.9139, \mathrm{p}$-value $=1.671 \mathrm{e}-09$

alternative hypothesis: significant effects

Hasilnya menunjukkan nilai p value di bawah 0,05, artinya Hipotesis nol tidak diterima dan sebaliknya, hipotesis alternatif diterima. Uji ini menunjukkan jika model Random Effect lebih baik daripada Pooling. Penggunaan pooling setelah melalui dua uji ini sudah tidak dapat lagi karena sudah dibuktikan tidak tepat baik uji pooling atau uji random efek.

3) Ketiga, Memilih model yang paling tepat antara Fixed Effect dengan Random Effect. Setelah uji Hausman akan diperoleh mode yang paling tepat untuk regresi data panel ini. Hasil Uji Hausman seperti ini .

Ho $=$ Regresi Panel Random Effect

$\mathrm{Ha}=$ Regresi Panel Fixed Effects

Hausman Test

data: Tobinq DAR + DER

chisq $=0.91311, \mathrm{df}=2, \mathrm{p}$-value $=0.6335$

alternative hypothesis: one model is inconsistent

Hasil menunjukkan bahwa menolak hipotesis nol atau $\mathrm{HO}$ jadi model yang paling tepat adalah random.

4) Keempat, Melakukan regresi data panel dengan model random effect. Hasilnya sebagai berikut:

Oneway (individual) effect Random Effect Model

(Swamy-Arora's transformation)

Call:

plm(formula $=$ Tobinq $\sim$ DAR + DER, data $=$ paneltobinq 2, model $=$ "random", index = c("Perusahaan", "Tahun"))

Balanced Panel: $\mathrm{n}=8, \mathrm{~T}=5, \mathrm{~N}=40$

Effects:

idiosyncratic

individual

var

std.dev

share

theta:

0.3672

0.6060

0.4

0.5506

0.7420

0.6 
Residuals:

Min.

$\begin{array}{ll}\text { 1st Qu. } & \text { Median } \\ -0.350254 & -0.074708\end{array}$

3rd Qu.

Max.

$-0.977977$

$-0.350254$

0.106930

2.785480

Coefficients:

$\begin{array}{lllll} & \text { Estimate } & \text { Std. Error } & \text { z-value } & \operatorname{Pr}(>|z|) \\ \text { (Intercept) } & 1.786432 & 0.417645 & 4.2774 & 1.891 \mathrm{e}-05^{* * *} \\ \text { DAR } & -2.087653 & 0.510836 & -4.0867 & 4.375 \mathrm{e}-05^{\text {***}} \\ \text { DER } & -0.069591 & 0.043000 & -1.6184 & 0.1056\end{array}$

$--$

Signif. codes

$: 0$ ‘***) 0.001

0.01

‘* 0.05 ? 0.1 ' 1

Total Sum of Squares : 22.526

Residual Sum of Squares: 15.489

R-Squared

$: 0.31236$

Adj. R-Squared

$: 0.27519$

Chisq: 16.8073 on 2 DF, p-value : 0.00022405

5) Kelima, melakukan uji normalitas untuk mengetahui apakah datanya tersebar. Hasilnya menunjukkan grafik dimana data tersebar dengan normal.

\section{Normal Q-Q Plot}

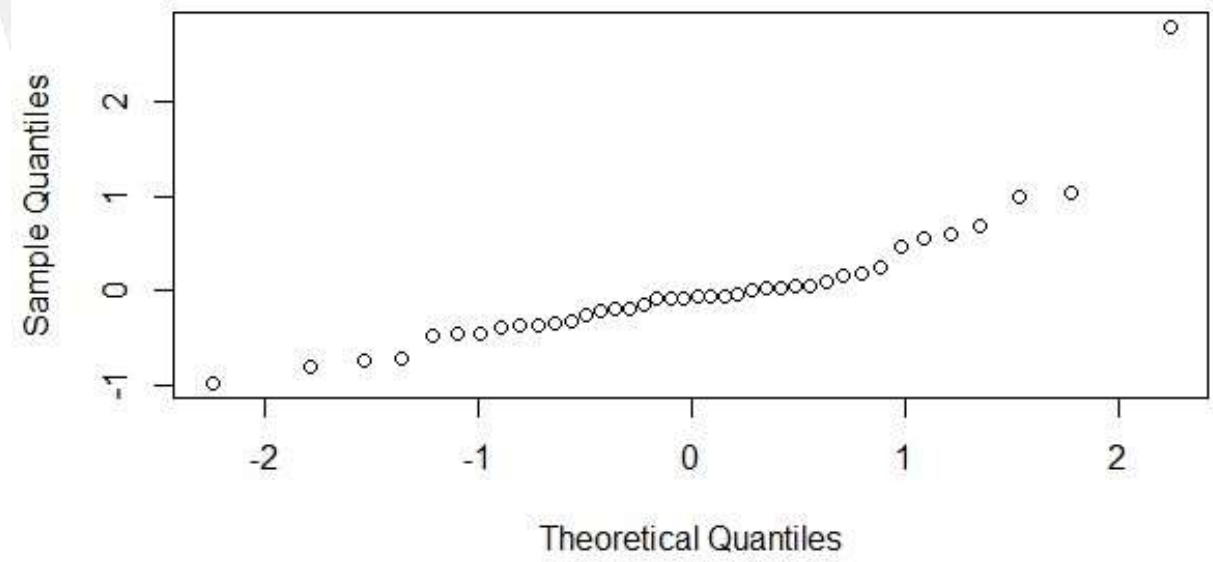

Untuk Uji Asumsi klasik adalah uji adalah uji mulitkolinearitas dan terlihat kalau uji multikolinearitas tidak terjadi karena nilai VIF di bawah angka 10. Sedangkan Uji autokorelasi dan juga uji heteroskedatisitas tidak perlu karena menggunakan metode generalized least square model random. 
Tabel 3. Nilai VIF Variabel Independen

\begin{tabular}{|r|r|c|}
\hline Variabel & DAR & DER \\
\hline Nilai VIF & 1,114552 & 1,114552 \\
\hline \multicolumn{3}{|c}{ Data (diolah) } \\
\hline
\end{tabular}

Dari hasil regresi diketahui kalau rasio Debt to Assset Ratio mempunyai hubungan yang signifikan dengan koefisien -2,087653. Artinya setiap kenaikan dari nilai DAR maka justru akan menurunkan dari nilai perusahaan sebesar -2,087652 satuan. Hal ini sesuai dengan yang ditemukan oleh Manurung dan kawan-kawan (2017).

Jika perusahaan menginginkan nilai perusahaan besar maka sebaiknya perusahaan juga harus menurunkan hutang yang dapat menurunkan nilai perusahaan. Untuk nilai Debt to Equity Ratio (DER) ternyata tidak signifikan. Struktur hutang atau perbandingan hutang dengan ekuitas tidak berpengaruh nyata. Ini sesuai dengan penelitian Dewi dan kawan-kawan (2014).

Kedua variabel baik DAR dan DER mempunyai hubungan yang signifikan secara bersamaan terbukti dengan nilai $F$ yang berada di bawah nilai $p<0.05$. Dengan nilai ini, model sudah dikatakan baik.

Nilai dari hutang (debt) jelas akan membuat perusahaan rentan akan risiko meski hutang sangat berguna pada peningkatan keuntungan. Penggunaan hutang yang tepat akan dapat menggerakkan atau menggairahkan perusahaan untuk menghasilkan pendapatan yang besar bagi perusahaan akan tetapi justru dengan kebanyakan hutang tersebut akan membuat perusahaan menjadi rentan terhadap kebangkrutan.

Secara keseluruhan maka kedua variabel ini mempunyai hubungan yang signifikan dengan nilai korelasi sebesar 31,326 . Hal ini berarti kalau kedua variabel tersebut sudah mempengaruhi setidaknya 31,326 \% sedangkan sisanya sekitar $68,673 \%$ dipengaruhi oleh variabel lain. 


\section{PENUTUP}

Hasil penelitian ini menunjukkan bahwa, terdapat hubungan signifikan antara variabel bebas dengan variabel tidak bebas dan hubungan individu yang ditandai oleh uji t, akan tetapi hubungannya terdapat beda arah.

Saran penelitian dalam spektrum luas dengan waktu yang lebih lama akan menunjukkan hubungan antara struktur modal dengan nilai perusahaan. Penelitian selanjutnya juga dapat menambah variabel-variabel lain yang dapat mencari variabel yang mempengaruhi dari nilai perusahaan.

\section{DAFTAR PUSTAKA}

Anderei. 2019. Debt to Equity Ratio dalam laporan keuangan web.id. investing. com. Tanggal 29/01/2019.

https://bit.ly/37v7JPf diakses 4/1/2020

Anderson,T.J, 2013. Value of Debt. Wiley Publication. https://bit.ly/3anF9Z2 diakses 18/9/2020

Baker, H.K and G.S Martin. 2011. Capital Structure and Financing Decisions: Theory, Evidence and Practice. John Wlley and Sons

Corelli, A. 2018. Analytical Corporate Finance. Second Edition. Springer https://www.google.com/url?sa=t\&rct=j\&q=\&esrc=s\&source=web\&cd $=2 \&$ cad $=$ rja\&uact $=8 \& v e d=2 a h U K E$ wiOgPm8sOTIAhUU6nMBHXvYCl MQFjABegQICRAC\&url=ftp\%3A\%2F\%2Fftp.repec.org\%2FRePEc\%2 Fwuk\%2Felecwp\%2Felecwp9608.pdf\&usg=AOvVaw0INGNi2Qc4QP biOmQyzCOz diakses 21/11/2019

Dewi, I. R., Handayani, S. R., dan Nuzula, N. F. 2014. Pengaruh Struktur Modal Terhadap Laba Perusahaan (Studi Pada Sektor Pertambangan yang Terdaftar di BEI tahun 2009-2012. Jurnal Administrasi Bisnis. https://bit.ly/2KTZPaA diakses 25/11/2019

Gibson. C. H. 2012. Financial Reporting and Analysis. Using Accounting Analysis https://bit.ly/2JsMDck

Sudana, I. M. 2019. Manajemen Keuangan Teori dan Praktik https://bit.ly/2L2Nd12 diakses 25/3/2020

Manurung, E. B., H. Siregar, and I.T. Saptono. 2016. Factor Affecting's TobinQ Coal Mining Registered at Indonesia Stock Exchange. Indonesia of Journal Business and Entrepreneurship.Vol.2 No.2 Juli 2016

https://bit.ly/3g42cmB diakses 25/3/2020 
Corporate Finance Institute

https://bit.ly/2VsOsZ8 diakses 14/09/2020

Kurniawan. Harga Batubara Terendah dalam Enam Bulan Terakhir, Bagaiman Prospek Emiten Batubara? 11 Desember 2018.

https://bit.ly/2VwZ35n diakses 21/09/2020 